\title{
HOW TO STRENGTHEN FLAT SLABS ON PUNCHING SHEAR - TRADITIONALLY WITH STEEL OR INNOVATIVE, BY USING FIBER COMPOSITE MATERIALS?
}

\author{
Tadeusz URBAN, Michał GOŁDYN* \\ Department of Concrete Structures, Lodz University of Technology, Al. Politechniki 6, 90-924 Łódź, Poland
}

Received 11 December 2018; accepted 14 January 2019

\begin{abstract}
In the paper the effectiveness of external steel and composite reinforcement was compared and discussed. The differences between the physical features of both materials, which are relevant for their use as additional, external reinforcement of the support zones, were presented. The results of authors' and others experimental studies on strengthening reinforced concrete slabs by using external longitudinal reinforcement in the form of CFRP strips and steel flat bars, as well as by increasing the stiffness od support zone with steel sheets and CFRP tapes, were discussed. It was stated that moderate effectiveness of composite materials as external punching shear reinforcement resulted from higher deformability of CFRP as well as premature deboning (prior to rupture of fibers).
\end{abstract}

Keywords: strengthening, concrete cover, punching shear, steel flat bars, composite materials, externally bonded strips, injected anchors.

\section{Introduction}

While reviewing professional literature and conference publications on the subject of strengthening the existing structures an impression can be made that composite materials are the dominant material used to strengthen building structures. This applies to all types of structures, not only to the reinforced concrete ones. Are the composite materials really used in engineering practice or only in research and publishing activities? Are the advantages of composite materials so significant that they will supersede the existing traditional solutions? The authors of the review paper will try to answer these questions by using their own experimental and professional experience. For this purpose, the results of authors' and others' experimental investigations were used. In the considerations the flat slabs strengthened against punching shear by means of external reinforcement will be taken into account. In the construction practice of monolithic reinforced concrete floors there is a tendency for the upper reinforcement to move down. For this reason the effective depth of the slab can be reduced. For slab-and-column structures, the support zone constitutes the integral point, which usually is decisive of the structure safety. The mass scale of applying the monolithic slab-and-column technology com- bined with quite a low level of workmanship, may result in numerous failures and even construction disasters in the future.

Figure 1 shows a typical example of a main reinforcement installation error in the support zone that was spotted by the author of the design because of the "odd" way in which the transverse reinforcement was stabilized. It was not possible to install the double-headed studs directly on the main reinforcement because the lower heads

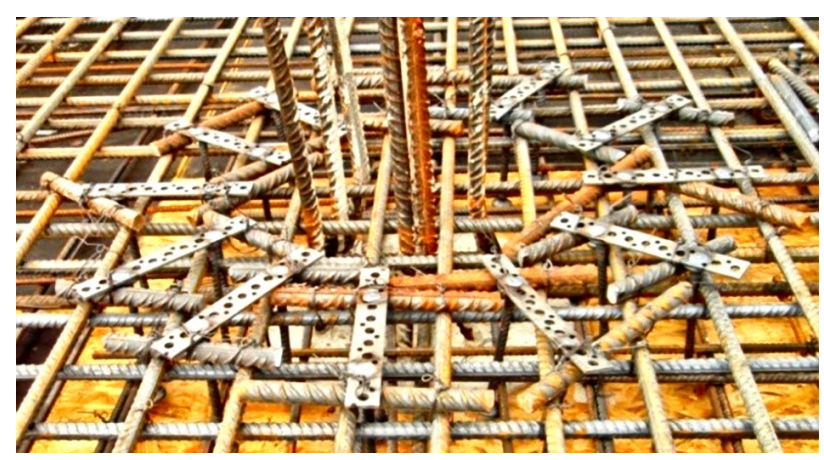

Figure 1. An example of moving down the top reinforcement by about $20 \mathrm{~mm}$ within the support zone of the flat slab

${ }^{*}$ Corresponding author. E-mail: michal.goldyn@p.lodz.pl 
were leaning against the formwork. To solve the problem, the workers used rebar sections as additional spacers. Nobody from the investor's supervision or the construction site management noticed the indicated execution errors present in all of the support zones of the building under construction. In the presented case the main longitudinal reinforcement became displaced downwards by about $20 \mathrm{~mm}$. Taking into account the total slab thickness of $200 \mathrm{~mm}$, this meant a reduction of effective depth of about $12 \%$. A more detailed analysis of the effective depth reduction on the of punching shear load carrying capacity of reinforced concrete slabs is presented in (Urban, Sitnicki, \& Tarka, 2013).

The example mentioned above demonstrates what the need for strengthening of existing structures on punching shear may arise from. One possible way of increasing the load carrying capacity of the support zones is the introduction of additional external reinforcement installed on the upper surface of the slab. In execution practice one may find solutions based on the use of steel (e.g. flat bars) or composite (for example, CFRP strips) elements for this purpose. Therefore, it makes sense to answer the question whether the two solutions can be treated as equivalent ones? In order to make an objective assessment an analysis of the physical properties of composite materials is necessary.

\section{Properties of composite materials significant from the design practice point of view}

Composite materials consisting of fibres (carbon, glass, aramid and basalt fibres, among others) that are embedded in epoxy resin constitute a relatively new solution. They are used more and more frequently in the implementation of various types of structural strengthening, the primary reason being their relatively low weight (and, therefore, ease of use) as well as resistance to the corrosive impact of water. Composite materials have a very high tensile strength, which exceeds the yield strength of typical B500 class reinforcing steel multiple times, not to mention the S235 structural steel normally used to make strengthening. Why then are there concerns regarding the use of composite materials as an alternative to classical reinforcement or reinforcement components, in spite of their excellent strength properties?

An unquestionable drawback of most typical composite materials is their relatively low modulus of elasticity that results from the properties of the resin in which the fibres are embedded. Depending on their type, Young's modulus usually falls within the $50 \div 170 \mathrm{GPa}$ range. Thus, it is lower than it is for steel. Consequently, one should expect larger strains at the same stress levels. One should also keep in mind that there is another risk that results from the strength properties of composite materials. These are linear-elastic materials throughout the entire stressstrain range. The lack of a plastic region excludes the possibility of failure that is ductile in nature - one that would be visible to users of the structure, allowing for an earlier response.

When making the decision to use composite materials, one should bear in mind that their physical properties are different from those of reinforcing steel. This is true for the differences in strength and deformation properties, as well as thermal expansion, long-term strength and the impact of moisture. In Table 1, according to ACI 440.1R-9 (American Concrete Institute, 2015) and PN-EN 1992-1-1 (Polish Standards Board, 2008), thermal expansion coefficients, typical for materials used in concrete structures, have been presented. Composite materials are characterized by strong anisotropy. It should be noted that an increase in the temperature of composites containing carbon and aramid fibres will cause a length reduction, while increasing transversal strains (this will be especially apparent in case of CFRP material). Thermal expansion coefficients differ significantly from values typical for concrete. Therefore, additional internal forces related to the difference in strain caused by temperature changes should be taken into account. As for the reinforced concrete elements such an unfavourable effect is almost nonexistent - steel and concrete are characterized by very similar thermal expansion coefficients in both directions.

In the fib design recommendations FIB Bulletin 40 (Federation for Structural Concrete, 2007) and ACI $440.1 \mathrm{R}-9$ there is one more risk pointed out - the difference in short- and long-term strength of composite materials subjected to tension. This effect is referred as creep rupture and is reflected by a delayed fibre rupture under a load that is constant over time. It is dependent on the environment in which the element is placed (temperature, UV radiation, and alkali content, among others) - especially apparent is the effect of water, which causes up to a $50 \%$ reduction in long-term strength. The unfavourable effect of rheological effects is particularly marked in case of GFRP materials whose long-term strength constitutes only $30 \%$ of the short-term strength. In case of composites containing carbon fibres (CFRP) this difference is not as clearly marked and stands at approximately 10\%. Experimental research (Scott \& Lees, 2009; Sivanendran \& Lees, 2015) has emphasized one more property that should take into consideration when using CFRP materials - it has

Table 1. Physical properties of materials used in engineering structures

\begin{tabular}{|c|c|c|c|c|c|}
\hline & Concrete & Steel & GFRP & CFRP & AFRP \\
\hline$\alpha_{l}\left[10^{-5} 1 / \mathrm{K}\right]$ & \multirow{2}{*}{1.0} & \multirow{2}{*}{1.0} & $0.6 \div 1.0$ & $-0.9 \div 0$ & $-0.6 \div-0.2$ \\
\cline { 1 - 4 }$\alpha_{t}\left[10^{-5} 1 / \mathrm{K}\right]$ & & & $2.1 \div 2.3$ & $7.4 \div 10.4$ & $3.3 \div 4.4$ \\
\hline
\end{tabular}

Notes: $\alpha_{l}$ - thermal expansion coefficient in longitudinal direction, $\alpha_{t}-$ thermal expansion coefficient in transverse direction. 
been established that they are capable of absorbing water. Water molecules enter into the resin matrix (ingressing the fibres) causing a swelling of the material (an increase in transverse strains is recorded). According to (Sivanendran \& Lees, 2015) the development of transverse strains depends on the square root of time the composite bar remains in contact with water. Transverse strains which come about as a result of composite "swelling" may lead to the development of cracks inside the elements, therefore, one should keep this phenomenon in mind when designing a concrete cover for this type of reinforcement.

The price of composite bars and strips can also be an important drawback. Depending on the type of fibres, their price can be up to $2 \div 10$ times higher than the price of reinforcing steel (Szumigała \& Pawłowski, 2014). The closest to steel bars, in terms of their price, are glass fibre bars, however, they are characterised by the lowest modulus of elasticity among the typical FRP composite materials.

\section{Effectiveness of punching shear strengthening by means of external reinforcement in light of experimental research results}

Composite materials are used by casting of new elements as well as for the strengthening of existing structures. The commonly used reinforcement techniques employing composite elements include:

- external strengthening by means of adhesive bonding of strips or wraps (externally bonded composites $\mathrm{EBC}$ ),

- injecting of strips into previously prepared grooves (near surface mounted composites - NSMC).

Previous experimental investigations indicated that because of premature strip debonding a full utilization of the composite material's strength properties is not possible in the case of external strip adhesive bonding. In order to reduce the drawbacks of this method it is proposed to inject the strips into grooves prepared in advance - since this increases the contact area with the adhesive relative to the cross-section of the strip. However, this method does have a fundamental limitation - the depth of the grooves is strictly limited by the concrete cover. By strengthening the structure the existing rebars must not be cut. Therefore to obtain a cross-section of reinforcement similar to that of adhesive strips bonded on the external surface, a much larger number of strips is required, such as was done, for example, in experimental studies by Moreno, Ferreira,
Bennani, Sarmento, and Noverraz (2015). They considered the effectiveness of the previously mentioned strengthening techniques by using CFRP composite strips: EBC and NSMC. The research series included four elements with identical longitudinal reinforcement: a specimen without transverse reinforcement (control), a model with classic bent-up bars used as punching shear reinforcement, and two models without transverse reinforcement strengthened before the experiment by means of CFRP strips. Unfortunately, the elements were made from different concrete mixes, which was reflected in the strength of the concrete, ranging between $26.4 \div 42.6 \mathrm{MPa}$. For this reason, a direct assessment of the effectiveness of the reinforcement is impossible because the strength of concrete of the so called control specimen (BC01) was nearly $60 \%$ higher compared to the strength of concrete used in the strengthened models. In order to roughly asses the effect of strengthening by means of composite strips, the reduced load carrying capacities $F_{\text {exp,re }}$ were used, which take into account the differences in the concrete strength of the control specimen $\left(f_{c, \text { comp }}\right)$ and the considered elements $\left(f_{c}\right)$ calculated according to the Equation (1):

$$
F_{\text {exp }, r e}=F_{\exp } \sqrt[3]{\frac{f_{c, c o m p}}{f_{c}}} .
$$

The results of the calculations are presented in Table 2. It should be noticed that the theoretical increase in load carrying capacity associated with the increase of the effective longitudinal reinforcement ratio $\rho_{l, t o t}$ (accounting for the differences in the moduli of elasticity of reinforcing steel and composite material) by approximately $55 \%$ resulted only in a a slight increase in load carrying capacity discernible only in the BCN1 model (with strips injected into previously prepared grooves) and equal to approximately $12 \%$.

Premature loss of adhesion of the reinforcement element precludes the possibility of full utilization of the composite material's strength properties. This was observable especially for the BCG1 model with adhesive bonded strips on the surface of the slab which became detached. Maximum strip strains measured directly before the failure of the elements considered in the research by Moreno et al. (2015) amounted to $1.5 \div 2.0 \%$ - see Figure 2. Thus, they were several times smaller than the ultimate strains at fibre rupture $\varepsilon_{f l, u}=12.1 \%$.

Experimental research by Ebead and Marzouk (2002) on the possibility of strengthening the support zones with

Table 2. The characteristics of the models considered in the research by Moreno et al. (2015)

\begin{tabular}{|c|c|c|c|c|c|c|}
\hline \multirow{2}{*}{ Model } & $\begin{array}{c}F_{\text {exp }} \\
{[\mathrm{kN}]}\end{array}$ & $\begin{array}{c}\rho_{l, s} \\
{[\%]}\end{array}$ & $\begin{array}{c}\rho_{l, \text { tot }} \\
{[\%]}\end{array}$ & $\begin{array}{c}f_{c} \\
{[\mathrm{MPa}]}\end{array}$ & $\begin{array}{c}F_{\text {exp }, \text { re }} \\
{[\mathrm{kN}]}\end{array}$ & $\begin{array}{c}F_{\text {exp }, \text { re }} \\
F_{\text {exp }, \mathrm{BC} 01}\end{array}$ \\
\hline BC01 & 176.8 & \multirow{2}{*}{1.33} & 1.33 & 42.6 & - & - \\
\hline BCN1 & 168.7 & 2.07 & 26.4 & 197.9 & 1.12 \\
\hline BCG1 & 155.0 & & 2.08 & 27.0 & 180.4 & 1.02 \\
\hline
\end{tabular}


$6.35 \mathrm{~mm}$ steel plates mounted on both surfaces of the floor and joined with steel bolts $19 \mathrm{~mm}$ (see Figure 3a) in diameter, showed such a solution to be highly effective. The location of the critical sections changed. The steel plates acted similarly to a reinforced concrete column head, which led to diagonal cracks being observed outside the reinforced zone after cutting the slab - see Figure $3 b$. The use of steel anchor plates allowed to increase the load carrying capacity of $\mathrm{A} 1 \div \mathrm{A} 4$ elements by about $33 \div 70 \%$ relative to the control specimen $\mathrm{C}$ [because of slight variations in the strength of concrete between the models, a reduced load carrying capacity was used, calculated similarly to Equation (1)]. Steel plates arranged around the entire perimeter of the column turned out to be the most effective (specimens $\mathrm{A} 1 \div \mathrm{A} 3$ ).

Encouraged by this success, Ebead and Marzouk (2004) in their research paper decided to analyse the effectiveness of a solution analogous to that described earlier, which involved the use of steel studs with a diameter of $\varnothing 19 \mathrm{~mm}$ and CFRP composite strips with a width of $100 \mathrm{~mm}$ (instead of steel plates). The considered method of strengthening is shown in Figure 4.

The failure of all specimens was violent, typical of punching shear. It was related to the appearance of an

a)

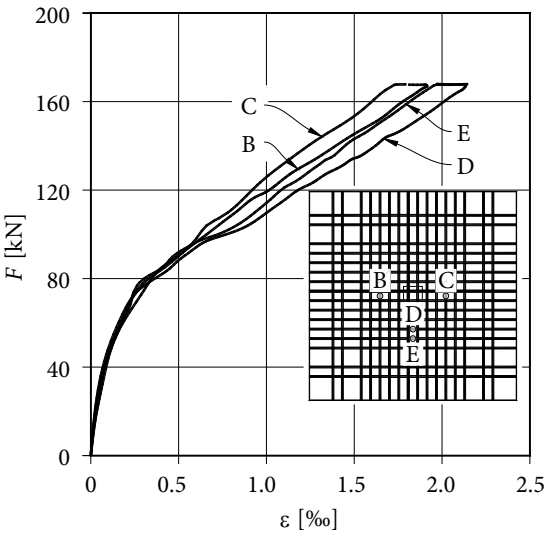

shear crack, whose outlet on the compressed side of the slab was located at a distance equal to approximately half of the effective depth of the slab $d$. In the research (Ebead \& Marzouk, 2002) it was pointed out that shear cracks formed outside the zone strengthened with steel plates (up to $1.5 d$ from the column edge), which means that a much longer critical perimeter was activated at failure. Ebead and Marzouk (2002) note that use of steel plates changed the failure mode to ductile, which was visible in the loaddeflection curves. The effectiveness of strengthening by means of composite strips was not as spectacular as it was when steel plates were used. Approximately on average a $15 \%$ increase in load carrying capacity was obtained, as compared with the control specimen C. The effectiveness of the strengthening was, therefore, approximately $20 \div 30 \%$ lower than that of the comparison model A3, even though the same number and arrangement of steel bolts was used. The observed differences most likely resulted from worse bolt anchoring conditions when CFRP strips were used.

The research by Sharaf, Soudki, and Van Dusen (2006) were focused on the effect of external composite reinforcement in the form of CFRP adhesive bonded strips on the slab surface. The effect of different strip arrangements was examined, as shown in Figure 5.

b)

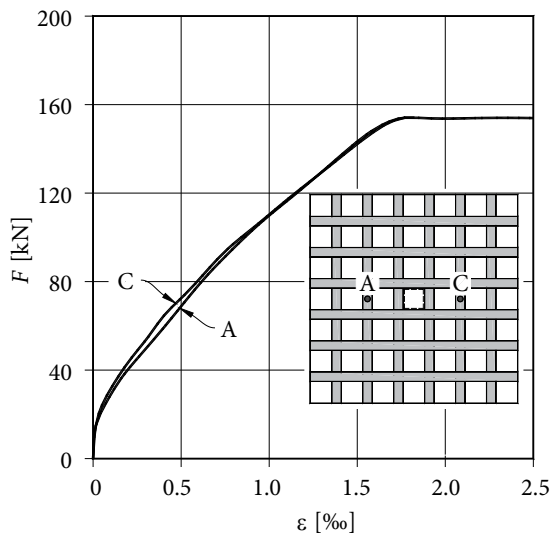

Figure 2. Comparison of strains of the CFRP external reinforcement in the form of: a) injected flat bars (BCN1), b) adhesive strips glued on the slab surface (BCG1), according to Moreno et al. (2015)

a)

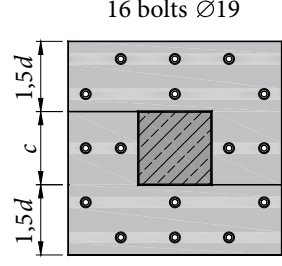

A1
12 bolts $\varnothing 19$

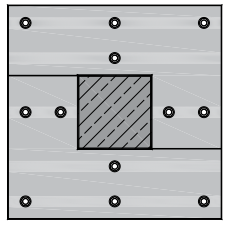

A2

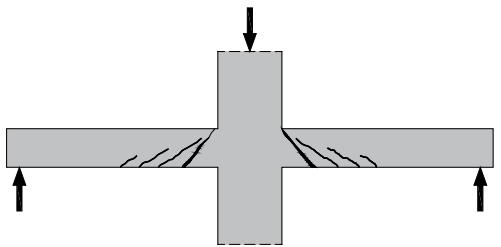

8 bolts $\varnothing 19$

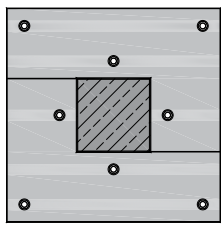

A3

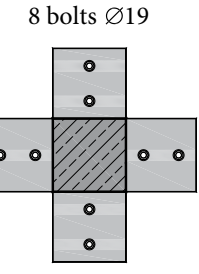

A4

b)

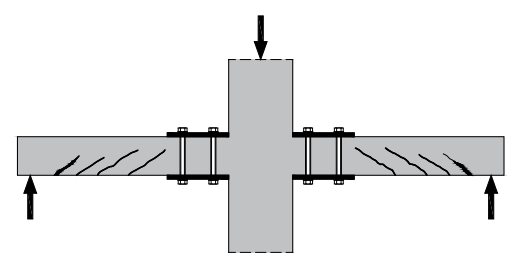

Figure 3. Specimens considered in the experimental investigations of Ebead and Marzouk (2004): a) the method of strengthening, b) typical crack pattern at saw-cuts of the specimens after the test (non-strengthened and strengthened) 
Based on the results of the tests, which are summarized in Table 3, a low efficiency of the applied solution can be stated. The introduction of composite strips resulted in an approximate increase of $4 \div 14 \%$ in the load carrying capacity with respect to the reference element. The best results were obtained when a larger number of strips was used (8 strips in total).

In order to assess the effectiveness of different strengthening methods in experimental research by Urban et al. (Urban, Sitnicki, \& Tarka, 2010; Urban \& Tarka, 2010) CFRP strips (series II) and steel flat bars (series III) were considered. All of the specimens were slabs with the following dimensions: $2300 \times 2300 \times 180 \mathrm{~mm}$. The longitudinal reinforcement constituted $\varnothing 12$ bars at $150 \mathrm{~mm}$ (top) and $\varnothing 8$ bars at $150 \mathrm{~mm}$ (bottom). All of the elements in a test series were made of concrete from one batch. Despite the differences in concrete age, there were no significant differences found in its strength at the day of the test of subsequent specimens. For this reason average strength $f_{c m}$ was used in further analysis. The view of the selected elements of series II and III after strengthening is shown in Figure 6.

In each test series, one of the models was used as

a)

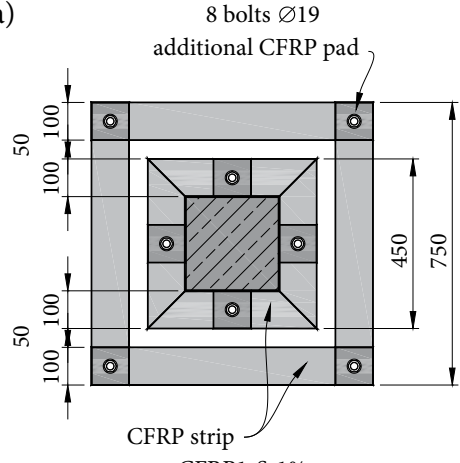

a reference element and was, therefore, not subject to strengthening. For the III series, in addition, the effect of the concrete cover on the punching shear load carrying capacity was examined. The cover of reinforcement of the S-3 element was $20 \mathrm{~mm}$, whereas for the other models of this series it was greater and equal to about $50 \mathrm{~mm}$. The information regarding the strengthening technique used for each of the specimens has been indicated in Table 4 , whereas the experimental load carrying capacities of the test specimens have been listed in Table 5. For the strengthening $80 \times 8 \mathrm{~mm}$ steel flat bars and $90 \times 1.4 \mathrm{~mm}$ CFRP composite strips were used.

The use of adhesive bonded CFRP strips allowed for a moderate increase of about $6 \%$ in the load carrying capacity of the WT-CF- 8 model compared to the reference element S-2. The WT-CF-8 specimen, similarly to the control element S-2, failed in a violent manner, which is typical for punching shear. The introduction of additional injected bolts allowed for an increase in the effectiveness of the strengthening, by preventing the adverse effect of strip debonding. The ultimate loads of the WTCF-K-8 and WT-CF-K-16 models were 23 and $31 \%$ higher than the load carrying capacity of the reference model.

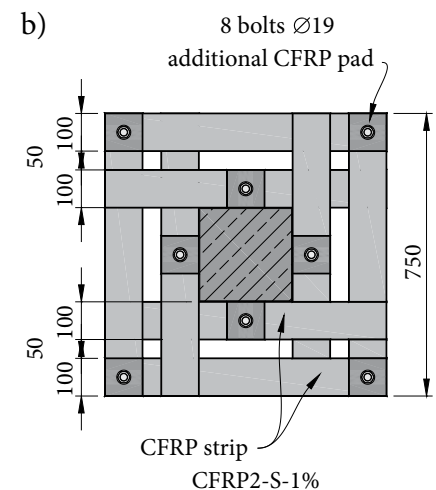

Figure 4. The method of strengthening of support zone considered in investigations (Ebead \& Marzouk, 2004)

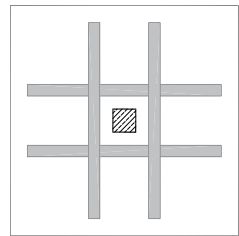

4-O-CFRP

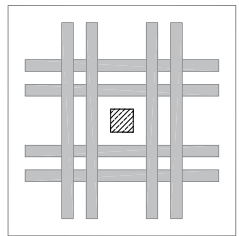

8-O-CFRP

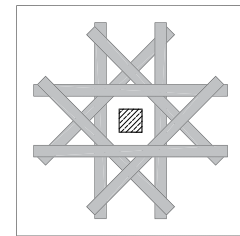

8-O\&S-CFRP

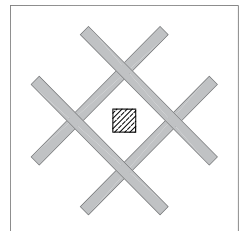

4-S-CFRP

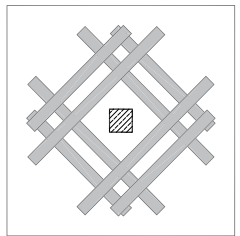

8-S-CFRP

Figure 5. The arrangement of the composite strips considered in the study by Sharaf et al. (2006)

Table 3. The characteristics of the models considered in the research by Sharaf et al. (2006)

\begin{tabular}{|c|c|c|c|c|c|c|}
\hline Model & $\begin{array}{c}d \\
{[\mathrm{~mm}]}\end{array}$ & $\begin{array}{c}\rho_{l} \\
{[\%]}\end{array}$ & $\begin{array}{c}f_{c} \\
{[\mathrm{MPa}]}\end{array}$ & $\begin{array}{l}F_{\exp } \\
{[\mathrm{kN}]}\end{array}$ & $\begin{array}{c}F_{\text {exp,re }} \\
{[\mathrm{kN}]}\end{array}$ & $\frac{F_{\text {exp,re }}}{F_{\text {exp, Control }}}$ \\
\hline Control & \multirow{6}{*}{114} & \multirow{6}{*}{1.40} & 28 & 421 & - & - \\
\hline 4-O-CFRP & & & 25 & 420 & 436.2 & 1.04 \\
\hline 4-S-CFRP & & & 28 & 451 & 451.0 & 1.07 \\
\hline 8-O-CFRP & & & 25 & 456 & 473.6 & 1.12 \\
\hline 8-S-CFRP & & & 25 & 462 & 479.8 & 1.14 \\
\hline 8-O\&S-CFRP & & & 28 & 477 & 477.0 & 1.13 \\
\hline
\end{tabular}


a)

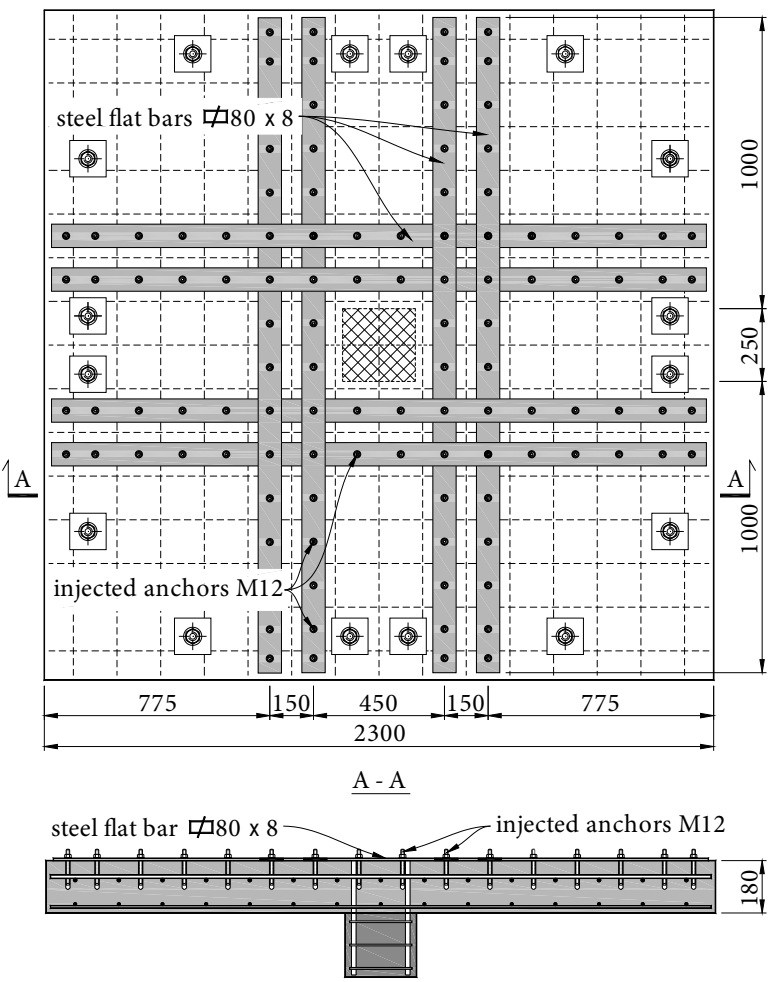

b)
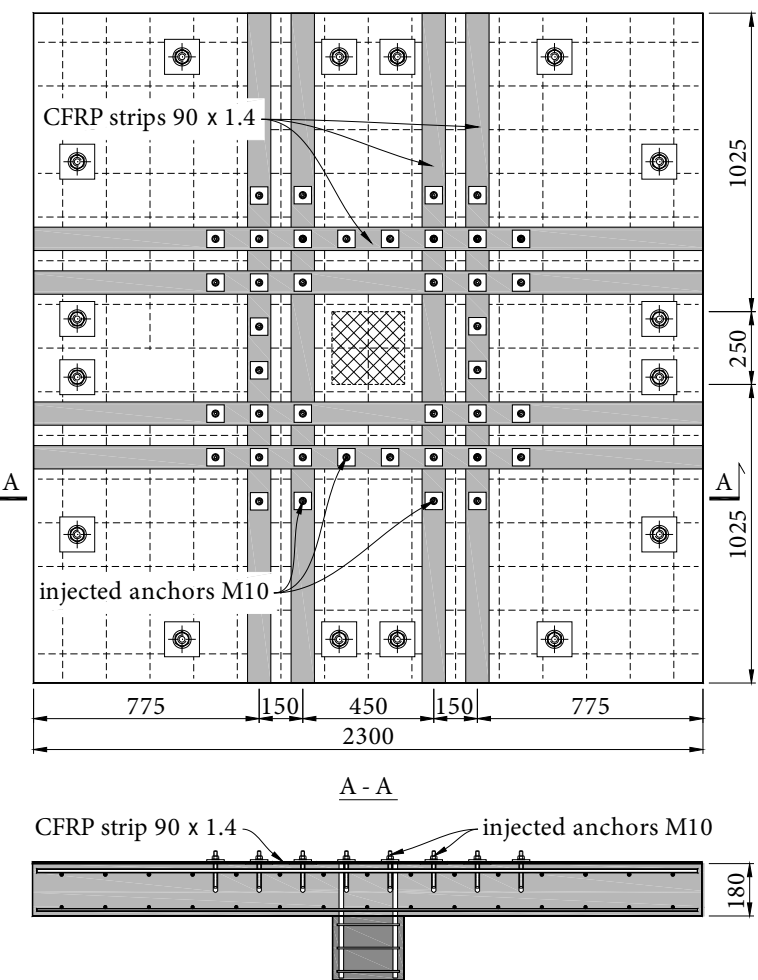

Figure 6. The specimens after strengthening, considered in the investigations of Urban et al. (2010), Urban and Tarka (2010): a) WPSK- ${ }^{\prime}$, b) WT-CF-K-8

Table 4. The method of strengthening of the models considered in the research by Urban et al. (2010), Urban and Tarka (2010)

\begin{tabular}{|c|c|c|}
\hline \multicolumn{2}{|r|}{ Model } & Method of strengthening \\
\hline \multirow{4}{*}{ Series I } & S-1 & control element - not subjected to the strengthening \\
\hline & WPS-8 & 8 flat bars anchored to the slab with M10 / M16 injected bolts \\
\hline & WPS-12 & 12 flat bars anchored to the slab with M10 / M16 injected bolts \\
\hline & WPSK-8 & 8 flat bars bonded to the slab and anchored with M10 / M16 injected bolts \\
\hline \multirow{4}{*}{ Series II } & S-2 & control element - not subjected to the strengthening \\
\hline & WT-CF-8 & 8 strips bonded to the slab \\
\hline & WT-CF-K-8 & 8 strips bonded to the slab and anchored with injected M10 bolts \\
\hline & WT-CF-K-16 & 16 strips bonded to the slab and anchored with injected M10 bolts \\
\hline \multirow{4}{*}{ Series III } & S-3 & control element - not subjected to the strengthening (nominal concrete cover - $20 \mathrm{~mm}$ ) \\
\hline & S-4 & control element - not subjected to the strengthening (increased concrete cover $-50 \mathrm{~mm}$ ) \\
\hline & WPSK8' & 8 flat bars bonded to the slab and anchored with M12 bolts (strengthened before the test) \\
\hline & WPSK8" & 8 flat bars bonded to the slab and anchored with M12 bolts (strengthened under load) \\
\hline
\end{tabular}

Their failure was milder in nature, which was visible especially in the case of the WT-CF-K-16 model (with double the number of strips). The loss of load carrying capacity was accompanied by the stripping of the anchor bolt threads.

The use of steel flat bars anchored to the slab turned out to be an effective solution. Compared to the reference models S- 1 and S-3, there was a $41 \div 58 \%$ and $84 \div 91 \%$ increase in load carrying capacity for elements of series I and III, respectively. The load carrying capacity of the WPSK- 8 model (with adhesive bonded and anchored flat bars) was about $58 \%$ higher than the load carrying capacity of the comparison model. For the second series of tests, the effectiveness of reinforcement, which involved the use of 8 CFRP strips anchored in the slab, was two times lower: the increase in load-bearing capacity of the WT-CF-K-8 model in relation to the S-2 reference element was about $23 \%$.

Strengthening under load (in conditions resembling the actual situation) resulted in an insignificant drop, of about $6 \%$, in effectiveness of strengthening. It is noteworthy that the use of external reinforcement in the form of steel flat bars allowed for the compensation of the execution error, which resulted in decrease of the effective depth of the slab. There was an increase of $42 \div 47 \%$ in load carrying 
Table 5. The characteristics of the models considered in the research by Urban et al. (2010)

\begin{tabular}{|c|c|c|c|c|c|c|c|}
\hline \multicolumn{2}{|c|}{ Model } & $\begin{array}{c}d \\
{[\mathrm{~mm}]}\end{array}$ & $\begin{array}{c}f_{c m} \\
{[\mathrm{MPa}]}\end{array}$ & $\begin{array}{c}\rho_{l} \\
{[\%]}\end{array}$ & $\begin{array}{l}F_{\exp } \\
{[\mathrm{kN}]}\end{array}$ & $\begin{array}{c}F_{c o r} \\
{[\mathrm{kN}]}\end{array}$ & $F / F_{\text {comp }}$ \\
\hline \multirow{4}{*}{ Series I } & $S-1^{*}$ & 147 & \multirow{4}{*}{44.8} & 0.49 & 500 & 504.5 & - \\
\hline & WPS-8 & 151 & & 0.48 & 730 & 710.3 & 1.408 \\
\hline & WPS-12 & 148 & & 0.49 & 750 & 750.0 & 1.487 \\
\hline & WPSK-8 & 152 & & 0.48 & 825 & 795.3 & 1.576 \\
\hline \multirow{4}{*}{ Series II } & $S-2^{*}$ & 145 & \multirow{4}{*}{38.8} & 0.51 & 495 & 508.9 & - \\
\hline & WT-CF-8 & 150 & & 0.49 & 550 & 540.1 & 1.061 \\
\hline & WT-CF-K-8 & 148 & & 0.50 & 625 & 625.0 & 1.228 \\
\hline & WT-CF-K-16 & 149 & & 0.49 & 675 & 668.9 & 1.314 \\
\hline \multirow{4}{*}{ Series III } & $S-3$ & 147 & \multirow{4}{*}{39.7} & 0.50 & 475 & \multirow{4}{*}{ - } & 1.293 \\
\hline & S- $4^{*}$ & 118 & & 0.62 & 367 & & - \\
\hline & WPSK-8' & 118 & & 0.62 & 700 & & 1.907 \\
\hline & WPSK-8” & 119 & & 0.62 & 675 & & 1.839 \\
\hline
\end{tabular}

Note: ${ }^{*}$ control elements - destructive force $\left(F_{\text {comp }}\right)$ constituted the reference level to determine the effectiveness of the strengthening.

capacity compared to the reference model S-3 (with the designed $20 \mathrm{~mm}$ cover), despite the fact that the thickness of the primary (rebar) reinforcement cover of the WPSK8 ' and WPSK-8 elements was higher and equal to $50 \mathrm{~mm}$.

Figure 7 shows the relation between the deflection $u$ and the applied load $F$. One can see a distinct effect of the external reinforcement on the stiffness of the slab. The increase in stiffness was proportionate to the number of CFRP strips used. The anchoring of strips had no impact on the stiffness of the WT-CF-K-8 model, which was similar to that of the WT-CF-8 element. When steel flat bars were used, a similar favourable stiffening effect was observed. The introduction of reinforcement when a load was applied on the WPSK-8" element resulted in a considerable increase in slab stiffness compared to the S- 4 control specimen. It should be noted that after the strengthening, the intensity of increase in deflections was similar to the one recorded for the WPSK-8' element (strengthened before the test). As a result of different deformations, the WPSK-8' reinforcement did not yield. For model WPSK8 ", stresses in the reinforcement reached the yield point, however the strain increase rate fell after installation of the external reinforcement.

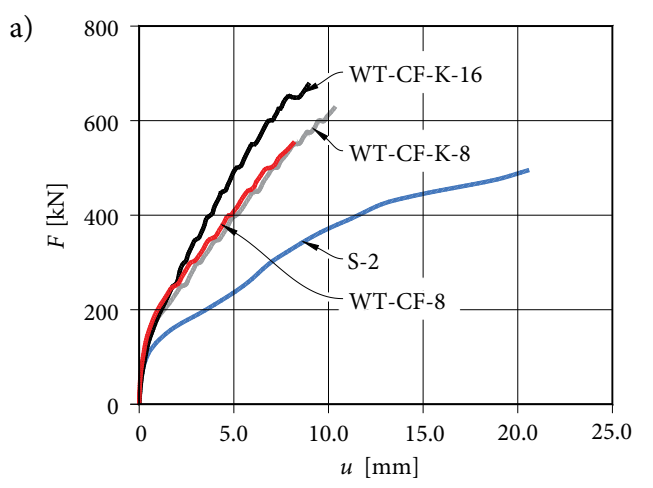

Figure 8 presents a comparison of strains of reinforcement components, measured near the column's corner, depending on the load level $F$ in relation to the destructive force $F_{\text {exp }}$. One can note a much higher intensity of strain increase in CFRP strips compared to steel flat bars. The maximum strip strains recorded at the failure amounted about $4.0 \%$ and they were much lower than the ultimate strains related to fibre rupture $-\varepsilon_{f l, u}=17.8 \%$. These observations are in line with the results presented in the following research papers Moreno et al. (2015) and Sharaf et al. (2006) among others. The rate of strain increase was significantly lower for the WPSK-8' element that was strengthened with steel flat bars. Directly before the failure approaching the yield point was recorded $\left(\varepsilon>\varepsilon_{p l}=1.599 \%\right)$.

Comparing the effectiveness of CFRP composite strip versus steel flat bar reinforcement techniques, one can draw the conclusion that the use of the first solution brought moderate results. In order to increase the utilization of the composite's strength properties, it was necessary to anchor the strips with steel bolts (which counteract the degradation by debonding).

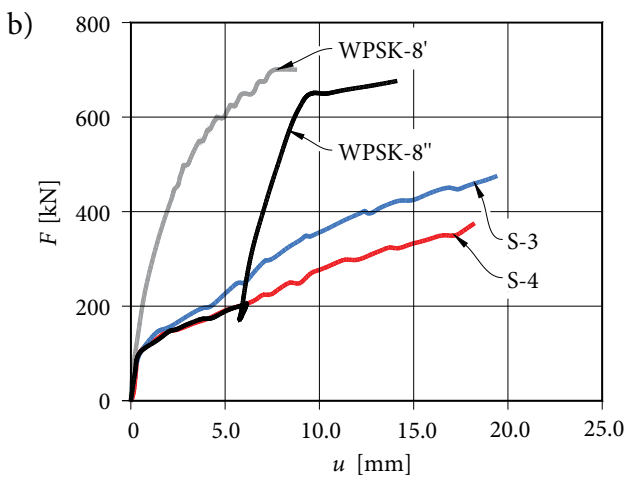

Figure 7. The relationship between load and the deflection of the specimens of: a) II ${ }^{\text {nd }}$, b) IIII ${ }^{\text {rd }}$ series considered by Urban et al. (2010) 

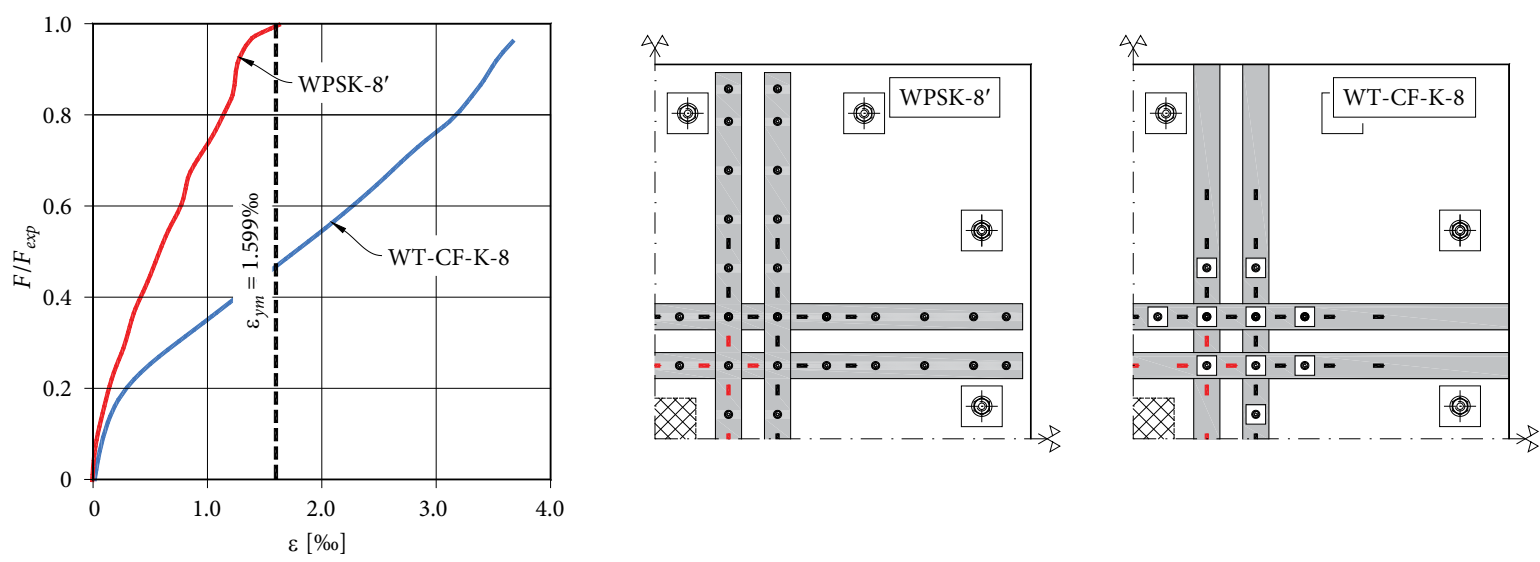

Figure 8. Comparison between strains of the external reinforcement of the specimens WT-CF-K-8 and WPSK- $8^{\prime}$ according to the load level $F / F_{\text {exp }}$, Urban et al. (2010)

Here the question must be asked about the cause of the relatively low effectiveness of CFRP composite strips as punching shear reinforcement. It goes without saying that the strips had a significantly smaller cross-section, more than five times smaller, than flat steel bars. However, if the load-bearing capacity of both cross-sections is compared, the following load carrying capacities are revealed:

- for steel flat bars: $N_{R}=A_{s} f_{y}=655 \cdot 325 \cdot 10^{-3}=212.9 \mathrm{kN}$,

- for composite strips: $N_{R}=A_{f f} f_{f l}=126 \cdot 3032 \cdot 10^{-3}=$ $380.9 \mathrm{kN}$

Therefore, it is evident that strips have about an $80 \%$ higher load carrying capacity than steel flat bars, despite their smaller cross-section. However, as experimental research has shown, it is impossible to use full of the strength of composite materials due to the lower modulus of elasticity. In the reported investigations the maximum recorded strain reached about $3.7 \%$, which amounts to
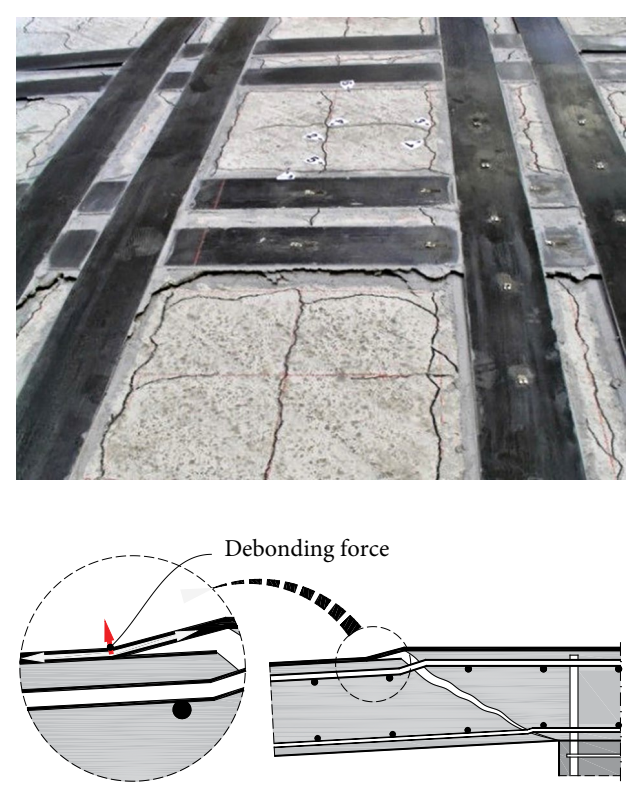

Figure 9. The failure mechanism on the edge of diagonal crack
$81.1 \mathrm{kN}$ per single strip, thus, $60 \%$ lower than the tensile force registered in steel flat bars. Furthermore, taking into account the difference between moduli of elasticity of CFRP and steel $\left(E_{f} / E_{s}=0.87\right)$, the effective cross-section of the strip with respect to steel reinforcement was lower and amounted to $0.87 \times 126=110 \mathrm{~mm}^{2}$. The cross-section of the external reinforcement increased by $440 \mathrm{~mm}^{2}$ in models with 4 strips in one direction, and by $880 \mathrm{~mm}^{2}$ in models with 8 strips, which constituted $25 \%$ and $50 \%$ of the primary rebar reinforcement, respectively. The effectiveness of CFRP strips turned out to be smaller than the effectiveness of steel flat bars for the following reasons:

- lower modulus of elasticity $\left(E_{f l}=174 \mathrm{GPa}\right)$,

- relatively small cross-section $\left(126 \mathrm{~mm}^{2}\right)$ in relation to flat bars $\left(640 \mathrm{~mm}^{2}\right)$,

- the inability to use the full strength of the strips as a result of the premature failure through debonding of the strip along the edge of the diagonal crack (an effect comparable to "ripping"), which came about even before the rupture of the fibres (see Figure 9).

\section{Conclusions}

The results of the experimental studies have shown that the possibility of effective strengthening of labs against punching shear by using CFRP composite materials may be very limited. The reason for that is mostly the inability to utilize the full strength of CFRP strips, as they may detach prematurely. The available CFRP strips have a small cross-section compared to typical steel flat bars. That is why they will be subject to higher strains at the same load, particularly when taking into account the typically lower modulus of elasticity of composite materials. Therefore, it should not come as a surprise that the traditional solutions in which steel is used are a popular choice in the engineering practice. The reinforcement of flat slab's support zones by means of steel flat bars discussed in the paper (Buda-Ożóg, Woliński, \& Kujda, 2017) can serve as an example of such an implementation. 


\section{References}

American Concrete Institute. (2015). Guide for the design and construction of structural concrete reinforced with fiber-reinforced polymer bars (ACI 440.1R-9). ACI Committee 440.

Buda-Ożóg, L., Woliński, S., \& Kujda, J. (2017). Ocena bezpieczeństwa płytowego stropu żelbetowego [Safety Assessment of RC Two-Way Slab Floor], In Proceedings of the Conference on Structural Failures, Międzyzdroje, Polska (pp. 761-772).

Ebead, U., \& Marzouk, H. (2004). Fiber-reinforced polymer strengthening of two-way slabs. ACI Structural Journal, 101(5), 650-659. https://doi.org/10.14359/13387

Ebead, U., \& Marzouk, H. (2002). Strengthening of two-way slabs using steel plates. ACI Structural Journal, 99(1), 23-31. https://doi.org/10.14359/11032

Federation for Structural Concrete. (2007). FRP reinforcement in $R C$ structures. (FIB Bulletin No. 40, Technical report).

Moreno, C., Ferreira, D., Bennani, A., Sarmento, A., \& Noverraz, M. (2015). Punching shear strengthening of flat slabs: CFRP and shear reinforcement. Paper presented at FIB Symposium, Copenhagen, Denmark.

Polish Standards Board. (2008). Eurokod 2 - Projektowanie konstrukcji z betonu - Część 1-1: Reguly ogólne i reguły dla budynków [Eurocode 2: Design of concrete structures - Part 1-1: General rules and rules for building] (PN-EN 1992-1-1). Warszawa.

Scott, P., \& Lees, J. M. (2009). Uptake swelling and thermal expansion of CFRP tendons. Proceedings of the Institution of Civil Engineers - Structures and Buildings, 162(4), 263-273. https://doi.org/10.1680/stbu.2009.162.4.263

Szumigała, M., \& Pawłowski, D. (2014). Zastosowanie kompozytowych prętów zbrojeniowych w konstrukcjach budowlanych [The use of composite reinforcing bars in engineering structures]. Przeglad Budowlany, 3, 47-50.

Sharaf, M. H., Soudki, K. A., \& Van Dusen, M. (2006). CFRP Strengthening for Punching Shear of Interior Slab-Column Connections. Journal of Composites for Construction, 10(5), 410-418.

https://doi.org/10.1061/(ASCE)1090-0268(2006)10:5(410)

Sivanendran, S., \& Lees, J. M. (2015). Interaction between CFRP tendons and concrete when subjected to long-term moisture exposure. Paper presented at FIB Symposium, Copenhagen, Denmark.

Urban, T., Sitnicki, M., \& Tarka, J. (2010). Badania połaczeń plyta-słup wzmacnianych zewnętrznie na przebicie [Investigation of column-slab connections externally strengthened on punching shear] (Report no 18). Department of Concrete Structures, Łódź, Poland.

Urban, T., Sitnicki, M., Tarka, J. (2013). Wzmacnianie na przebicie płyt żelbetowych $\mathrm{z}$ błędnie usytuowanym zbrojeniem głównym [Strengthening of the reinforced concrete slabs with faulty placed reinforcement]. Inżynieria i Budownictwo, 69(9), 479-483.

Urban, T., \& Tarka, J. (2010) Strengthening of Slab-Column Connections with CFRP. Archives of Civil Engineering, 56(2), 193-212. https://doi.org/10.2478/v.10169-010-0010-0 